\title{
Dynamic Causal Modeling of Spatiotemporal Integration of Phonological and Semantic Processes: An Electroencephalographic Study
}

\author{
Gaëtan Yvert, ${ }^{1,2,3,4}$ Marcela Perrone-Bertolotti, ${ }^{1,2}$ Monica Baciu, ${ }^{1,2}$ and Olivier David ${ }^{3,4,5}$ \\ ${ }^{1}$ Laboratoire de Psychologie et Neurocognition, UMR CNRS 5105, 38040 Grenoble, France, ${ }^{2}$ Université Pierre Mendès-France, 38040 Grenoble, France, \\ ${ }^{3}$ Université Joseph Fourier, Fonctions Cérébrales et Neuromodulation, 38700 La Tronche, France, ${ }^{4}$ INSERM, U836, Grenoble Institut des Neurosciences, \\ 38700 La Tronche, France, and ${ }^{5}$ Clinique de Neuroradiologie et Unité IRM, Pôle Imagerie, Centre Hospitalier Universitaire, 38042 Grenoble, France
}

Integration of phonological and lexicosemantic processes is essential for visual word recognition. Here we used dynamic causal modeling of event-related potentials, combined with group source reconstruction, to estimate how those processes translate into context-dependent modulation of effective connectivity within the temporal-frontal language network. Fifteen healthy human subjects performed a phoneme detection task in pseudo-words and a semantic categorization task in words. Cortical current densities revealed the sequential activation of temporal regions, from the occipital-temporal junction toward the anterior temporal lobe, before reaching the inferior frontal gyrus. A difference of activation between phonology and semantics was identified in the anterior temporal lobe within the 240-300 ms peristimulus time window. Dynamic causal modeling indicated this increase of activation of the anterior temporal lobe in the semantic condition as a consequence of an increase of forward connectivity from the posterior inferior temporal lobe to the anterior temporal lobe. In addition, fast activation of the inferior frontal region, which allowed a feedback control of frontal regions on the superior temporal and posterior inferior temporal cortices, was found to be likely. Our results precisely describe spatiotemporal network mechanisms occurring during integration of phonological and semantic processes. In particular, they support the hypothesis of multiple pathways within the temporal lobe for language processing, where frontal regions would exert a top-down control on temporal regions in the recruitment of the anterior temporal lobe for semantic processing.

\section{Introduction}

Performing a language task with visually presented stimuli involves completion of several operations, such as visuo-orthographic and grapheme-to-phoneme decoding, phonological and semantic analyses, with lexical retrieval and word recognition (Jobard et al., 2003). Identifying brain network mechanisms associated with these different components of language, e.g., spatiotemporal processes as revealed by chronometry of brain electrical responses or by functional neuroimaging, is important.

Reading written words generates first a visuo-orthographic analysis that mainly involves occipitotemporal cortical areas [Brodmann areas (BA) 18, 19, 37] (Greenblatt, 1976; Warrington and Shallice, 1980; Damasio and Damasio, 1983; Henderson, 1986; Cohen et al., 2000; Leff et al., 2001; Dehaene et al., 2002; Gaillard et al., 2006). An associated electroencephalographic (EEG) component is a negative wave above occipitotemporal regions at $150 \mathrm{~ms}$ after stimulus presentation (N150) (Gros et al., 2002; Cohen and Dehaene, 2004; Brem et al., 2005).

Received Dec. 23, 2011; revised Feb. 7, 2012; accepted Feb. 10, 2012.

Author contributions: G.Y., M.P.-B., and O.D. designed research; G.Y. and M.P.-B. performed research; G.Y., M.P.-B., M.B., and 0.D. contributed unpublished reagents/analytic tools; G.Y. and 0.D. analyzed data; G.Y., M.P.-B., M.B., and O.D. wrote the paper.

This study was supported by Région Rhône-Alpes. We thank Dr. Vladimir Litvak for his methodological support.

Correspondence should be addressed to Dr. Olivier David, Grenoble Institut des Neurosciences, Chemin Fortuné Ferrini, Bât EJ Safra, CHU, 38700 La Tronche, France. E-mail: odavid@ujf-grenoble.fr.

DOI:10.1523/JNEUROSCI.6434-11.2012

Copyright $\odot 2012$ the authors $\quad 0270-6474 / 12 / 324297-10 \$ 15.00 / 0$
Phonological analysis includes grapheme-to-phoneme conversion (Berndt et al., 1994), decoding and retrieval of sound forms of the written words (Herbster et al., 1997; Fiez et al., 1999; Walter et al., 2001; Alario et al., 2003; Simon et al., 2006). Manipulating phonemes and phonological forms of the words involves the superior temporal gyrus (BA 22) (Pugh et al., 1996; Vandenberghe et al., 1996; Lurito et al., 2000; Billingsley et al., 2001; Vigneau et al., 2006) and the inferior frontal gyrus (pars triangularis and opercularis; BA 44, 45) (Zatorre et al., 1992; Dapretto and Bookheimer, 1999; McDermott et al., 2003; Seghier et al., 2004).

Semantic processing requiring lexical retrieval of semantic representations is supposed to take place within inferior frontal (BA 47) and middle and inferior temporal regions (BA 21, 37) (Billingsley et al., 2001; Jobard et al., 2003; Gitelman et al., 2005). Semantic processing also involves the anterior temporal lobe (Fujimaki et al., 2009; Binney et al., 2010; Visser et al., 2010), which might convert modality-specific information into amodal representations to extract all semantic attributes (Marinkovic et al., 2003; Patterson et al., 2007; Lau et al., 2008).

In a meta-analysis (Jobard et al., 2003), arguments for a dualroute model of reading were provided. In short, this model assumes that graphophonological decoding and phonological analysis on the one hand, and lexicosemantic processing on the other hand, are segregated into two parallel pathways. In a recent functional magnetic resonance imaging (fMRI) study using dynamic causal modeling (DCM) (Richardson et al., 2011), three potential processing streams from occipital to temporal cortices 
were described: a ventral lexicosemantic route, a dorsal phonological route, and an intermediate route encompassing partially both ventral and dorsal route.

Here, we describe spatiotemporal organization of phonological and semantic processing using EEG recordings performed in 15 healthy participants during two separate language tasks involving phonological or semantic processing of visual stimuli. First, we proceed to group-level source reconstruction (Litvak and Friston, 2008) to describe the sequence of activation of brain regions involved. Second, we specifically test the face validity of the dual-route model (Jobard et al., 2003) using DCM of eventrelated potentials (ERPs) (David et al., 2006; Kiebel et al., 2006).

\section{Materials and Methods}

\section{Participants}

Fifteen French volunteers ( 4 females, 11 males; age range, 23-26 years; mean age, 24.5 years) underwent EEG recording. All participants were righthanded as assessed by the Edinburgh Handedness Inventory (Oldfield, 1971) and had normal or corrected-to-normal vision and no previous neurological episodes or history of substances abuse. They gave informed written consent to the study, which was approved by the Ethics Committee of Grenoble University Hospital (No. ID RCB: 2010-A01063-36).

\section{Stimuli and tasks}

Participants were asked to perform two language tasks during one EEG session: phoneme detection in pseudo-words (Perrone-Bertolotti et al., 2011) and semantic categorization (Cousin et al., 2007) in words presented in visual modality. Both tasks were performed separately in two distinct sessions, which were counterbalanced across subjects, to avoid needing to distinguish words and pseudo-words that would have involved confounding processes at the lexical level. Across both tasks, we controlled the number of letters and syllables, as well as the bigram and trigram frequencies, according to Lexique 2 database.

Phoneme detection. Stimuli were 192 legal French pseudo-words (5-7 letters length) built by exchanging two or three letters in French concrete nouns. Half of the items were considered "target" and contained the target phoneme to be detected $(/ \mathrm{o} /)$. The grapheme-to-phoneme conversion for the phoneme /o/ had two levels of difficulty. For half of the target items, the grapheme representation was simple (Target $\mathrm{S}$ ) as phoneme /o/ corresponded to grapheme "o" (e.g., obalet, clotir, damulo). For the other half, the grapheme representation of phoneme /o/ was complex (Target $\mathrm{C}$ ) as the sound /o/ corresponded to graphemes "au" (e.g., autril, phaumi, amilau). Furthermore, the phoneme /o/ was presented an equivalent number of times at the beginning (e.g., autril or obalet), middle (e.g., phaumi or clotir), and end (e.g., amilau or damulo) of the pseudo-words. Participants were asked to judge whether the pseudowords contained the sound /o/ or not. They were instructed to internally pronounce the item, without articulation or verbalization.

Semantic categorization. Stimuli were 192 words (5-7 letters length). Half of the items were target and described living entities (plants and animals). The other half represented nonliving entities. They were selected from Lexique 2 database for French (New et al., 2004). Lexical frequencies of words and the number of letters (between 5 and 7) were controlled between both conditions. Participants were asked to judge whether the word described a living or nonliving entity. They were instructed to read words without articulation or verbalization.

Stimuli were generated using E-Prime software (Psychology Software Tools) running on a PC. Stimuli were written in white Courier New, font size 24, centered in the middle of a black screen, and presented for 1000 ms. A fixation cross was presented between stimuli. Participants performed manual responses by pressing two keys on a keyboard with the index and the middle finger of the right hand. Each trial lasted $2.5 \mathrm{~s}$ and consisted of $500 \mathrm{~ms}$ fixation cross, $1000 \mathrm{~ms}$ pseudo-word/word presentation, and $1000 \mathrm{~ms}$ fixation cross for providing the response. The reaction time (RT) and the accuracy [percentage correct responses (\%CR)] were recorded for each participant to evaluate the performance of task execution. Each task lasted $\sim 8 \mathrm{~min}$.

\section{EEG acquisition}

After positioning the electrodes on the scalp, participants were seated in a comfortable chair in front of the projection screen $(70 \mathrm{~cm}$ distance). During sessions and between trials, they were asked to fixate a cross in the middle of the screen and to refrain from moving and blinking. EEG data were recorded using $96 \mathrm{Ag}$ - $\mathrm{AgCl}$ active electrodes (BrainCap; Brain Products) positioned according to the standardized 10-20 system. EEG signals were recorded continuously with a sampling rate of $500 \mathrm{~Hz}$ and electrode impedances were kept at $<5 \mathrm{k} \Omega$. Reference and ground were taken at $\mathrm{FCz}$ (midline, central frontal) and $\mathrm{AFz}$ (midline, anterior frontal), respectively. Positions of the 96 electrodes were obtained as follows: the three fiducials (nasion, left ear, right ear) and six well distributed electrodes (Fp1, Fp2, P3, P4, Cz, Oz) were measured manually with calipers (Koessler et al., 2007). Those measures were then used to obtain the positions of all electrodes after computation of the affine transformation that best fitted the canonical EEG cap provided in SPM8 onto the head of each subject (Wellcome Trust Centre for Neuroimaging, http://www.fil.ion.ucl.ac.uk/spm/).

\section{EEG processing}

EEG data were processed using SPM8 for EEG software (update 4290).

EEG preprocessing. Continuous EEG data were down-sampled to 250 $\mathrm{Hz}$, bandpass filtered between 1 and $30 \mathrm{~Hz}$ (Butterworth filter), and converted to average reference. They were then epoched and baselinecorrected from -500 to $1000 \mathrm{~ms}$, where time 0 is stimulus onset. Trials including eyes movements $(>80 \mathrm{mV})$, muscular artifacts (high frequencies), and poor responses (wrong answer or reaction time of more than a second) were excluded from further analysis (on average over subjects, for phonologic and semantic tasks respectively, $84.43 \pm 9.33 \%$ and $82.67 \pm 8.86 \%$ of trials were kept). ERP were obtained by averaging epoched trials for each subject and each task.

Statistical analyses of ERP. Statistical analyses of ERP at the group level were performed according to the SPM procedure (Kilner and Friston, 2010). First, ERP amplitudes for each subject and each condition were transformed into scalp maps of dimension $64 \times 64$ pixels obtained for the 375 time bins using a two-dimensional (2D) linear interpolation [knowing electrode coordinates in the Montreal Neurological Institute $(\mathrm{MN})$ space]. Second, scalp maps of ERP amplitudes were concatenated over time to produce a three-dimensional (3D) volume (2D space $\times$ time). Third, the scalp-time 3D volume was smoothed using a low-pass kernel [ $9 \mathrm{~mm} \times 9 \mathrm{~mm} \times 20 \mathrm{~ms}$, full width at half magnitude $(\mathrm{FWHM})]$ to obtain data that could be approximated to a Gaussian random field in the absence of effect. Group statistics on this scalp-time volume were finally obtained using a one-sample $t$ test to detect common responses to both conditions and a paired $t$ test to detect differences between conditions. Statistical analyses were performed from $-500 \mathrm{~ms}$ up to $1000 \mathrm{~ms}$ and were corrected for multiple comparisons by controlling the familywise error (FWE) rate across space and time.

Cortical source imaging. Task-related cortical current source densities were obtained from ERP using an inversion procedure. A canonical mesh (cortex, skull, skin) was used to ensure that cortical activity was reconstructed in the same source space over subjects (Mattout et al., 2007). The meshes were warped to each subject's anatomy using an inverse spatial normalization defined with the three fiducials and the electrode coordinates. The canonical cortical mesh was composed of 8196 vertices. A boundary element method (BEM) head model composed of three layers (inner skull, outer skull, and scalp with respective conductivities of: 0.33 , 0.0041 , and $0.33 \mathrm{~S} \cdot \mathrm{m}^{-1}$ ) was then used to calculate the forward model that links cortical activity to scalp measurements (Phillips et al., 2007). Cortical current source densities were obtained using the group inversion procedure described in Litvak and Friston (2008). It is based on a hierarchical model with multiple sparse priors for bioelectric source imaging (Friston et al., 2008) with a particular hyperprior that imposes consistency on the source reconstruction over conditions and subjects. In other words, source reconstruction in each individual analysis was confined to the same locations and only amplitudes of cortical current densities were allowed to be modulated by the task. The temporal window of inversion was set between $200 \mathrm{~ms}$ prestimulus and $600 \mathrm{~ms}$ poststimulus. Two inverse solutions at the group level were performed: (1) pooling together both experimental conditions to focus on differences of 
Table 1. ROls used for DCM

\begin{tabular}{llllll}
\hline & & & \multicolumn{3}{c}{ MNI coordinates } \\
\cline { 5 - 6 } ROI & Abbreviation & Brodmann's area & $x$ & $y$ & $z$ \\
\hline Occipito-temporal junction & OT & $19 / 37$ & \pm 42 & -84 & -5 \\
Posterior inferior temporal sulcus & IT & 37 & \pm 62 & -52 & -12 \\
Posterior superior temporal & & & & & \\
$\quad$ sulcus & STS & $21 / 22$ & \pm 60 & -40 & 2 \\
Anterior temporal pole & AT & 38 & \pm 54 & 0 & -20 \\
Inferior frontal gyrus & IFG & $45 / 47$ & \pm 50 & 28 & -10 \\
\hline
\end{tabular}

MNI coordinates indicate the positions of equivalent current dipoles.

amplitude of activation and (2) separating experimental conditions to focus on differences of source location. The second option was only chosen to optimize the choice of regions of interest (ROI) used in DCM (see Dynamic causal modeling, below) after finessing the source analysis in the 140-240 ms range, which contains the second ERP component corresponding to early processing of both tasks in occipital-temporal regions. For every subject and condition, 3D images in the MNI space of the energy of current density was obtained every $20 \mathrm{~ms}$ by applying a temporal Gaussian kernel of 20 ms FWHM to cortical time series and an isotropic Gaussian kernel of 9 mm FWHM used for spatial resampling.

Group-level T-statistics of 3D images of cortical energy were obtained using a standard random-effect analysis in SPM8. The image of every poststimulus time window was contrasted against a baseline time window located between -100 and $-80 \mathrm{~ms}$ peristimulus time. Small volume correction for multiple comparisons was applied to a $10 \mathrm{~mm}$ radius sphere centered on the cluster of activation ( $p<0.005$, uncorrected). Final statistical threshold was set at $p<0.05$, FWE corrected for multiple comparisons at the cluster level.

Dynamic causal modeling. DCM for ERP explains ERP as a resultant of stimulus-related changes in the activity of neuronal populations (David et al., 2006; Kiebel et al., 2006). Each cortical source is represented by three interconnected populations (pyramidal cells, excitatory interneurons, and inhibitory interneurons) representing different cortical layers. Different sources are connected by long-range connections conforming to physiological connectivity rules (Felleman and Van Essen, 1991). Differences in interregional effective connectivity afford changes in the shape of ERP between conditions. The models and their constitutive sources are first specified according to functional hypotheses of interaction across brain structures of interest. Second, model parameters are inferred from the ERP and the evidences of models are computed using Bayesian procedures (Penny et al., 2004). Finally, Bayesian model selection (BMS) is applied to define the most plausible model (Stephan et al., 2009) or family of models (Penny et al., 2010). It computes the expected probability of obtaining a given model for any randomly selected subject in the group, and the exceedance probability, which is the belief that a particular model is more likely than any other model (of all models tested), given the group data. The BMS procedure takes into account not only the goodness of fit of the data, but also the complexity of the models (i.e., number of free parameters) to avoid overfitting the data. Averaged parameters of relatively similar, but different, models can be obtained or each subject using Bayesian model averaging (BMA), which averages the parameters of the different models weighted by their posterior probability (Trujillo-Barreto et al., 2004). Inference at the group level on connectivity parameters obtained after BMA of selected models can then be performed to identify significant changes of connectivity between conditions.

Dynamic causal models (DCMs) were constructed with five ROIs identified from our source localization results (Table 1, see also Figs. 3, 4): occipitotemporal junction (OT), posterior part of inferior temporal (IT), posterior part of superior temporal (STS), anterior temporal (AT), and inferior frontal gyrus (IFG). Each ROI was modeled with an equivalent current dipole (ECD) (Kiebel et al., 2006), which was positioned symmetrically in each hemisphere on the maximum of activation clusters obtained after group source reconstruction (for MNI coordinates, see Table 1). Note that, to keep the models as simple as possible, we did not explicitly include early relays within the visual thalamus and primary visual cortex. This early activity is implicitly modeled in the shape of the extrinsic input to OT, which is estimated from the data, assuming identical early visual processing between conditions. All models included a ventral pathway (OT/IT/AT), a dorsal pathway (OT/STS/AT), and reciprocal connections between IT and STS (Richardson et al., 2011). They were symmetric across hemispheres, including lateral nontaskmodulated connections between homologous regions. Sixteen models were designed to test three hypotheses (Fig. 1): (1) the level in the cortical hierarchy of connectivity modulation within the dorsal and ventral routes (just before or just after STS/IT), (2) the presence of a fast pathway toward IFG that could facilitate the top-down influence of IFG on lower regions (Cornelissen et al., 2009), and (3) the feedback pathway of IFG on STS or IT or both. These 16 models were computed with and without modulation of intrinsic connections, i.e., between neuronal populations within a given ROI, resulting in the study of 32 models. The evidence of all models was assessed on ERP time series taken between 0 and $450 \mathrm{~ms}$ peristimulus time. DCM options when adjusting data were chosen as follows: eight modes for data reduction, one discrete cosine transform component to remove slow drift, Hanning windowing to ensure convergence and limit the effect of late components (after $350 \mathrm{~ms}$ ), and no constraint on the orientation symmetry of ECD to favor differences of activation between left and right hemispheres. Models were compared at the group level using random effect (Stephan et al., 2009). Families of models (Penny et al., 2010) were also compared to test four hypotheses (Fig. 1): (1) hierarchical level of connectivity modulation (Models 1-4, 9-12, 17-20, and 25-28 vs Models 5-8, 13-16, 21-24, and 29-32), (2) OT/IFG connectivity (Models $1-8$ and 16-24 vs Models 9-16 and 2532), (3) position of IFG feedback (without feedback Models 1, 5, 9, 13, 17 , 21, 25, and 29 vs feedback on STS Models 2, 6, 10, 14, 18, 22, 26, and 30 vs feedback on IT Models 3, 7, 11, 15, 19, 23, 27, and 31 vs feedback on both IT and STS Models 4, 8, 12, 16, 20, 24, 28, and 32), (4) presence of intrinsic modulation (Models 1-16 vs Models 17-32).

\section{Results}

Behavior

Statistical analysis of \%CR revealed that phonological (mean $=$ $84.43 \%$; $\mathrm{SD}=9.33 \%)$ and semantic $($ mean $=82.67 \%$; $\mathrm{SD}=$ $8.86 \%$ ) tasks were performed correctly. No significant difference $(p=0.8)$ was obtained between tasks in terms of accuracy. However, RT was significantly higher $\left(t_{(14)}=3.7 ; p<0.01\right)$ for the semantic task (mean $=673.34 \mathrm{~ms} ; \mathrm{SD}=50.55 \mathrm{~ms}$ ) than for the phonological task (mean $=720.25 \mathrm{~ms} ; \mathrm{SD}=32.74 \mathrm{~ms})$. Because basic linguistic features (sublexical level), i.e., number of letters, phonemes and frequencies of bigrams and trigrams, were equivalent for both tasks, the difference of execution speed is more likely to have been related to high-level processes, i.e., lexical or semantic.

\section{ERP}

Root mean square (RMS) of the ERP amplitude averaged over subjects and electrodes showed, for each condition, three main components occurring at $112 \mathrm{~ms}$ (P100), $196 \mathrm{~ms}$ (N170/N200), and $332 \mathrm{~ms}$ (P350) with respect to stimulus onset (Fig. 2A,B). Tracking of ERP changes over time at the group level revealed propagation of the activity from occipital toward temporal electrodes and before reaching left frontal regions, for both language tasks. The P100 was detected on the posterior electrodes, predominantly in the right hemisphere in the vicinity of the occipital electrode PO8. The N170/N200 spread from left temporaloccipital electrodes $(160 \mathrm{~ms})$ toward more central region (200 $\mathrm{ms})$. The cortical wave of activation finally converged in bilateral temporal regions $(240 \mathrm{~ms})$. The maximum of the $\mathrm{P} 350$ was detected on left frontal electrodes (320-340 ms). Paired $t$ tests between task conditions revealed statistical differences only between 240 and 300 ms on left temporal electrodes $\left(t_{(14)}=4.8, p<0.001\right.$, uncorrected; Fig. $2 C$ ). Time series averaged over those electrodes showed during 


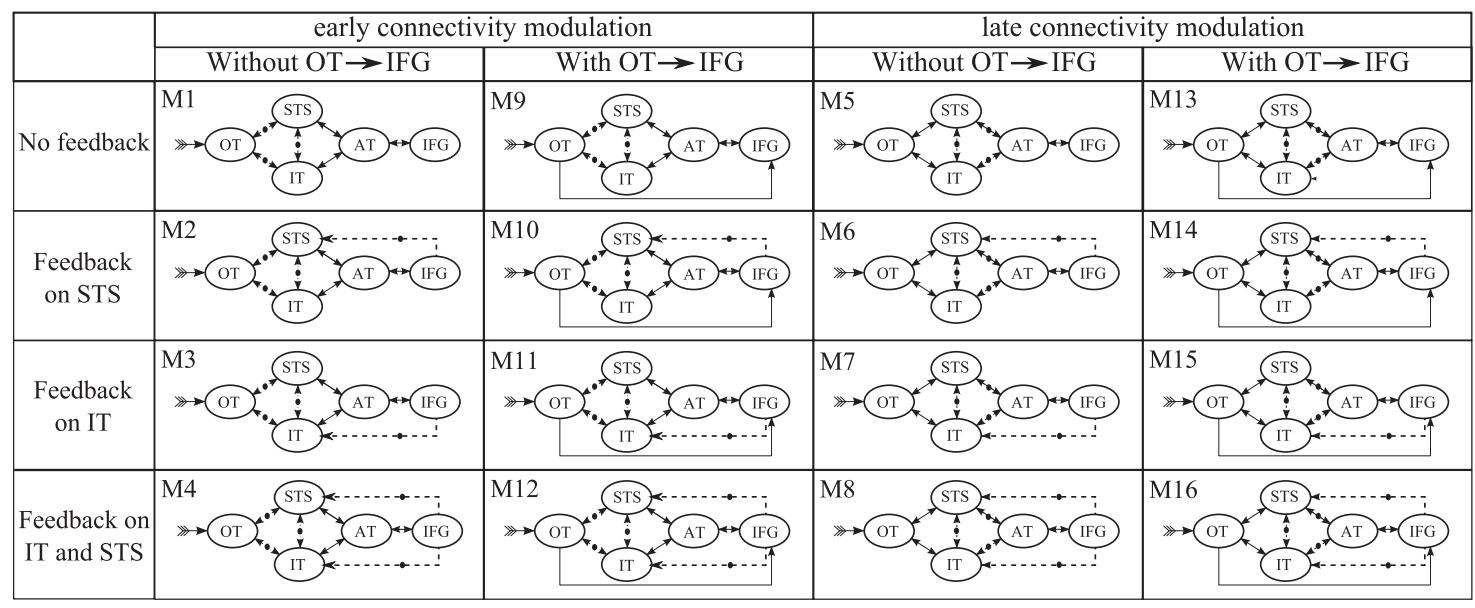

Figure 1. List of DCMs [Models 1 (M1) to 32 (M32)]. Stimulus extrinsic input is on 0T. All connections between regions of the same hemisphere are bidirectional (forward and backward). Models are symmetrical between left and right hemisphere, with nonmodulated bidirectional lateral connection between homologous regions (data not shown). Dashed lines indicate connections modulated between conditions. The two main columns show differences in the hierarchical level of the presence of connectivity modulation. Under both early connectivity modulation and late connectivity modulation, the left column shows models with slow activation of IFG and the right column shows models with a direct connection between $0 T$ and IFG. The four rows show different feedback from IFG. These 16 models were tested without (M1-M16) or with (M17-M32) intrinsic modulations on all sources.

this time period a difference in the slope of the ERP between the N200 and P350 components (Fig. 2D).

\section{Cortical source imaging}

To find the common network for both phonological and semantic tasks, current source densities were first estimated using ERP obtained for both conditions, from 100 to $350 \mathrm{~ms}$ (Fig. $3 A$ ). The P100-P140 observed on occipital electrodes was estimated to originate from the right inferior and middle occipital gyri. The N150 was located in the left inferior occipital-temporal cortex. From 160 to $220 \mathrm{~ms}$, the positive ERP was located across superior, middle, and inferior temporal gyri, bilaterally but more predominant on the left. From 220 to $260 \mathrm{~ms}$, the activations spread across the temporal lobe from the inferior gyrus to the anterior pole, bilaterally. After $260 \mathrm{~ms}$, the activations spread from the temporal pole toward the inferior frontal gyrus bilaterally. The difference of cortical activation between both conditions was marginally significant ( $p<0.001$, uncorrected) between 240 and $300 \mathrm{~ms}$ only. It was located within the anterior part of the temporal lobe, predominantly to the left, and corresponded to higher responses of this region during the semantic task (Fig. 3B).

To clarify whether feedforward information transferred through the temporal lobe involved, not only different activation strength, but also different regions between semantic and phonological processing, ERP were also group-inverted using the same methodology, but separately for each condition, between 140 and $240 \mathrm{~ms}$ (Fig. 4). Between 140 and $160 \mathrm{~ms}$, both tasks activated the inferior part of the occipital-temporal cortex, whereas, between 160 and $180 \mathrm{~ms}$, activation for the phonological task moved to the upper part of the posterior temporal cortex and activation for the semantic task remained in the posterior part of the inferior temporal cortex. Between 180-220 ms, activations moved toward more anterior regions for the phonological task in the upper bank of the temporal cortex and for the semantic task in the posterior part of the temporal cortex. Finally, at $\sim 220-240 \mathrm{~ms}$, activation of both tasks converged in the inferior part of the anterior temporal cortex. This result suggests subtle differences in early temporal pathways between the two tasks that were included in the DCMs.

\section{Dynamic causal modeling}

Bayesian model selection at the model level indicated Model 14 as being the most plausible one (Fig. 5A). This model included a fast connection from OT to IFG, a feedback from IFG to STS, and a late modulation of temporal connectivity. Interestingly, the selection of this model could not be attributed solely to its complexity, because complexity of Models 8,9 , and 15 was equivalent, and most of the models with intrinsic modulation (Models 1732) were more complex than Model 14. Although comparison of model families clearly indicated a modulation between higher temporal regions rather than between lower ones (Fig. $5 B$ ) and a direct connection from OT to IFG (Fig. $5 C$ ) in accordance with the winning model, comparison of families depending on the target of the feedback was not conclusive except that a feedback was strongly needed, either on STS, IT, or STS/IT (Fig. 5D). Finally, models with or without modulation of intrinsic connectivity were equally likely (Fig. 5E).

According to these results, we considered the family of six models (Models 14-16 and their homologues with intrinsic modulation: Models 30-32) that comprised the most likely features (anterior level of modulation, connection between OT and IFG, feedback from IFG) and applied the BMA procedure to obtain connectivity parameters of that family for both conditions. A paired $t$ test on the log connectivity parameters revealed a significant increase ( $p<0.05$, Bonferroni corrected) of the connectivity from IT to AT in the semantic task compared with the phonological task (Fig. 6). In addition, we found an increase of connectivity between IT and STS in the semantic condition compared with the phonological one. It was not significant $(p=$ 0.17 , Bonferroni corrected) when testing log connectivity parameters estimated from BMA, but reached significance $(p<0.05$, Bonferroni corrected) when testing log connectivity parameters averaged across models using the standard averaging procedure, i.e., without weighting by the posterior probability of models.

On average, cortical time series did not differ much between conditions. Only a marginal effect ( $p<0.1$, uncorrected) was found at the level of left AT at $\sim 240 \mathrm{~ms}$. In addition, a strong left predominance was mostly found in AT. Note also that DCM IFG time series did not show any strong activity after $250 \mathrm{~ms}$, as op- 

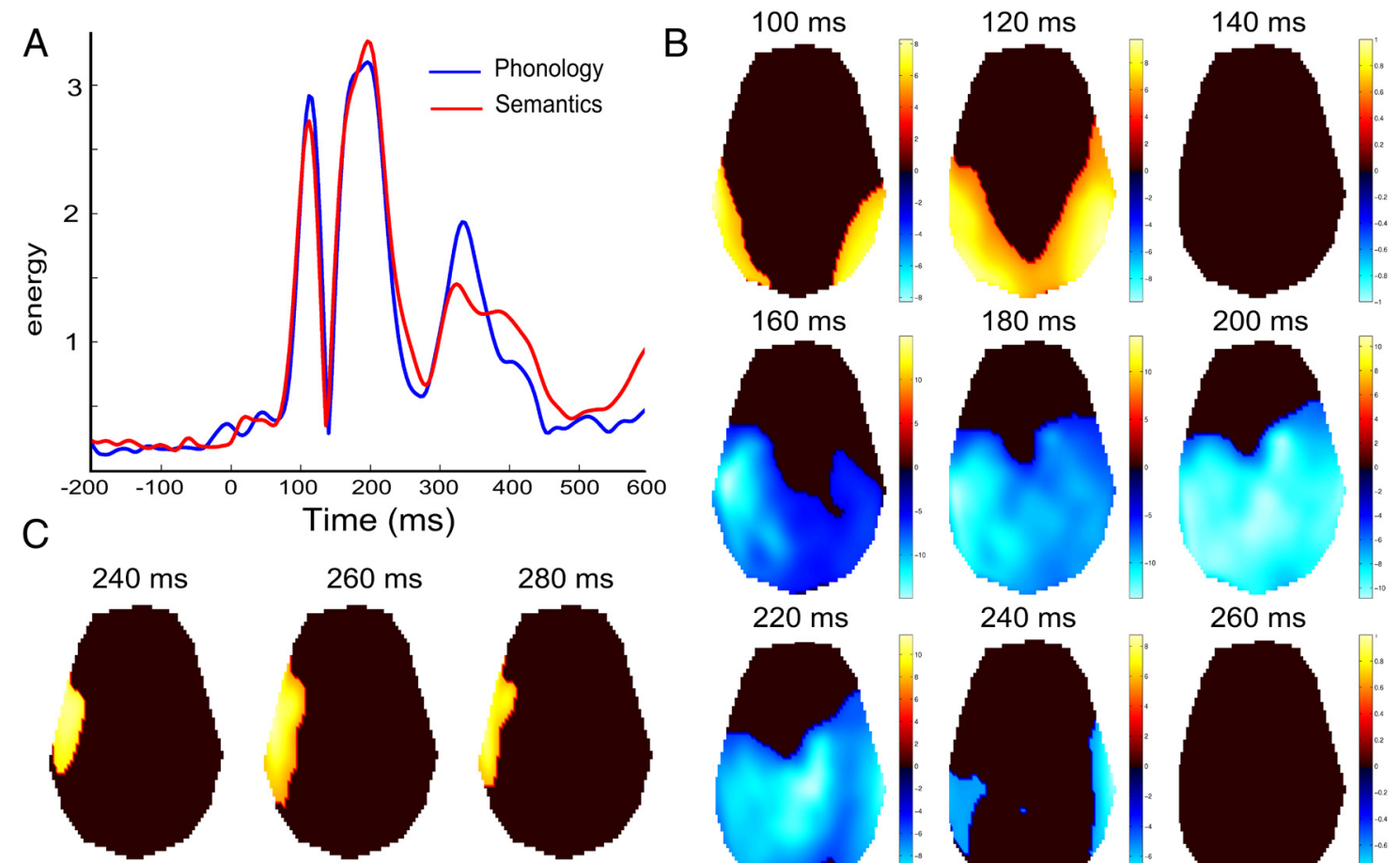

$160 \mathrm{~ms}$

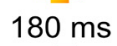

$200 \mathrm{~ms}$
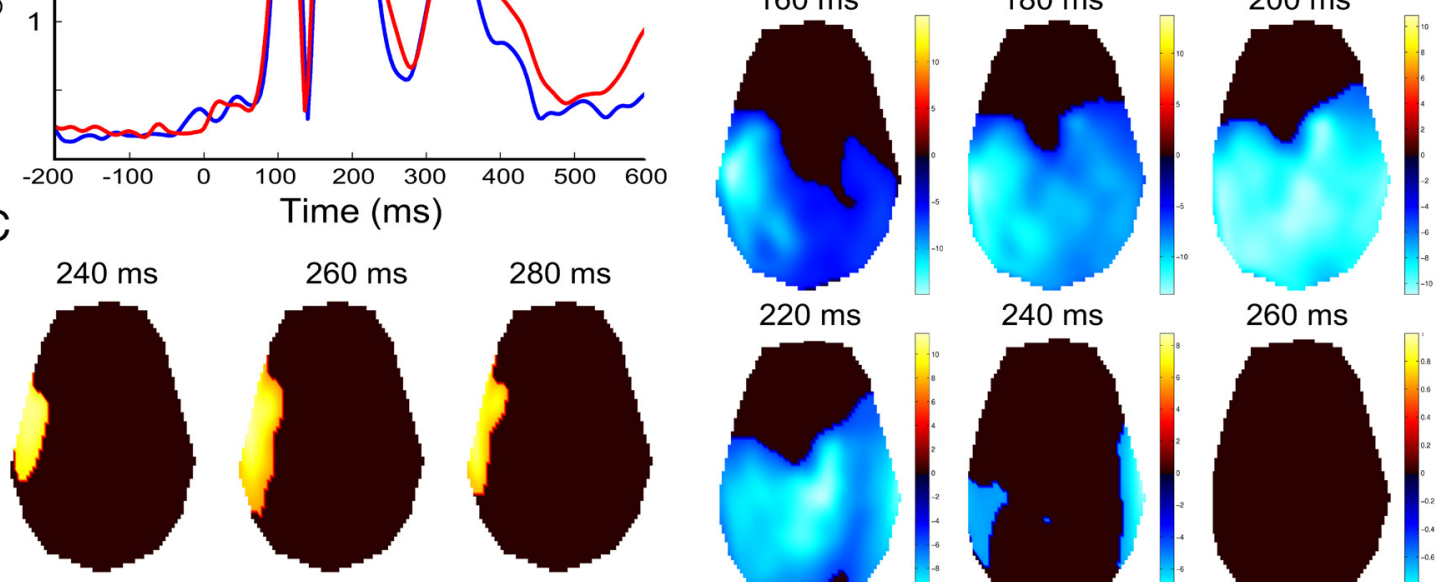

$220 \mathrm{~ms}$

$240 \mathrm{~ms}$
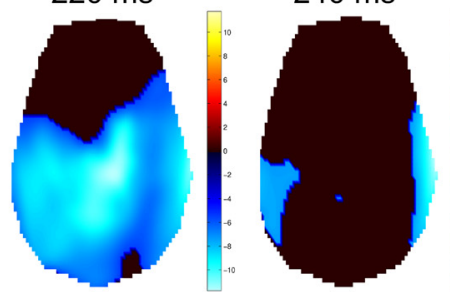

$260 \mathrm{~ms}$

$\begin{array}{lllllllll}-4 & -3 & -2 & -1 & 0 & 1 & 2 & 3 & 4\end{array}$

D
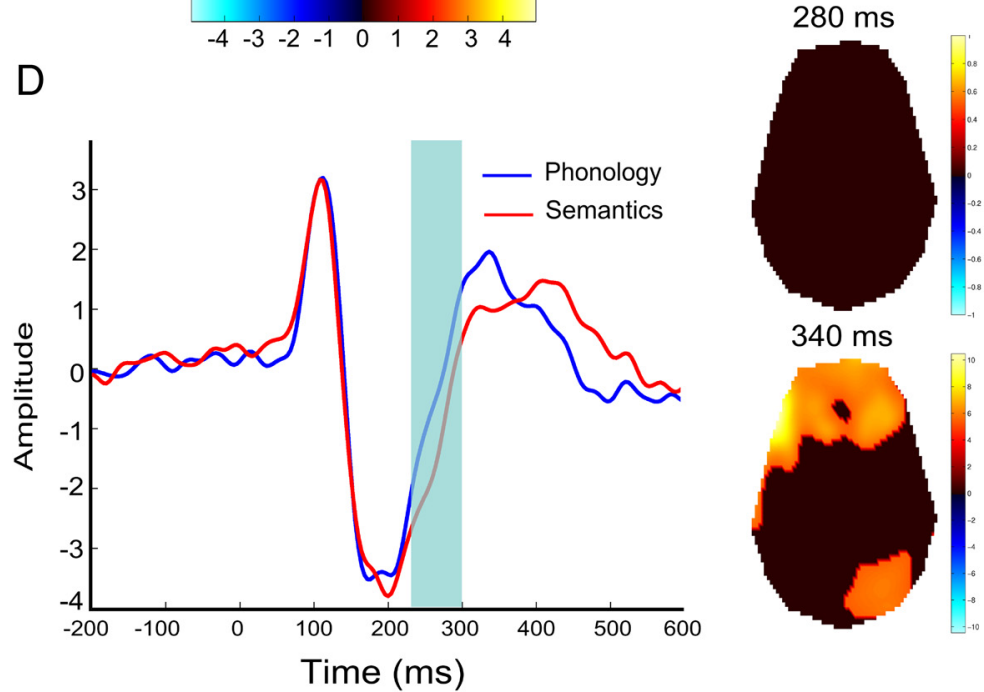

$300 \mathrm{~ms}$
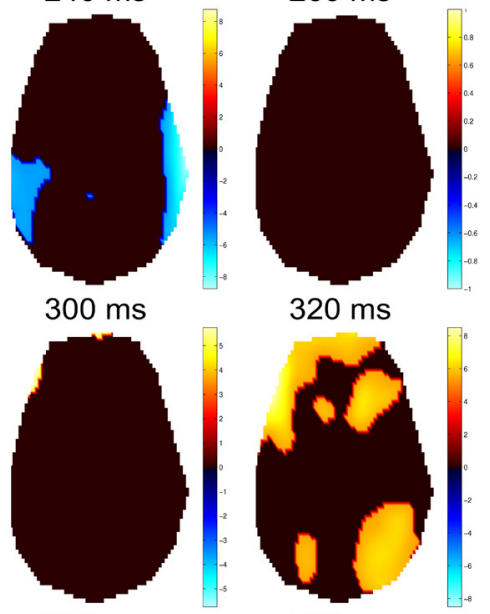

$320 \mathrm{~ms}$

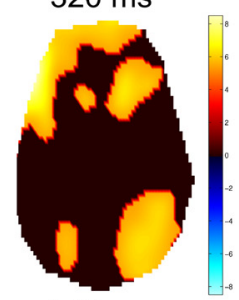

$340 \mathrm{~ms}$

$360 \mathrm{~ms}$
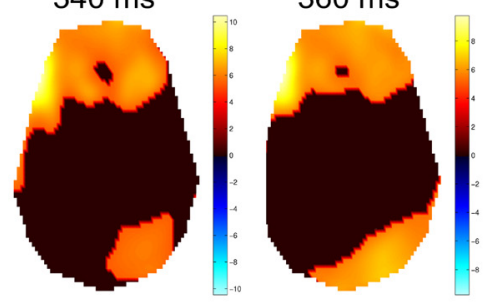

$380 \mathrm{~ms}$

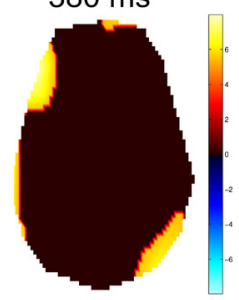

Figure 2. A, RMS time series averaged over subjects and electrodes showing three major ERP components peaking at $112 \mathrm{~ms}$ (P100), 196 ms (N170/N200), and 332 ms (P350). B, ERP scalp distribution for both conditions. One-sample $t$ tests every $20 \mathrm{~ms}$ of scalp time images threshold at $p<0.05$ corrected for multiple comparison (FWE) at both spatial and temporal level. C, Paired $t$ test between semantic and phonologic condition thresholded at $p<0.001$ (uncorrected) at 240, 260, and $280 \mathrm{~ms}$. D. Time series averaged over left temporal electrodes showing significant difference between conditions (shaded area).

posed to cortical current densities. A post hoc analysis revealed that the fit of the data by DCM was excellent, except after $280 \mathrm{~ms}$, where data on a few left frontal and right parietal electrodes were not well fitted (results not shown).

\section{Discussion}

The aim of this EEG study was to identify the spatiotemporal organization of brain response to word recognition by using phonological and semantic tasks. We based our work on the assumptions of the dual-route model of word reading (Jobard et al., 2003), which considers two specific pathways, one for phonological and one for semantic processing. It is in line with a recent DCM study in fMRI showing multiple routes from occipital to temporal cortex during reading (Richardson et al., 2011). Meth- odologically, we measured the neural responses using group source reconstruction (Litvak and Friston, 2008) and DCM analyses (David et al., 2006).

Our main results suggest different pathways for word recognition and processing. One pathway, that links the occipitaltemporal junction to the anterior temporal cortex via ventral temporal regions, would be predominantly required for the semantic task. Another pathway, also linking the occipitaltemporal junction to the anterior temporal cortex, but going through dorsal temporal regions, would be required more for lexicophonological processing. In addition, DCM indicated fast activation of inferior frontal cortex, suggesting top-down effects on the posterior part of the temporal lobe, and an increase of forward connectivity from inferior posterior to 

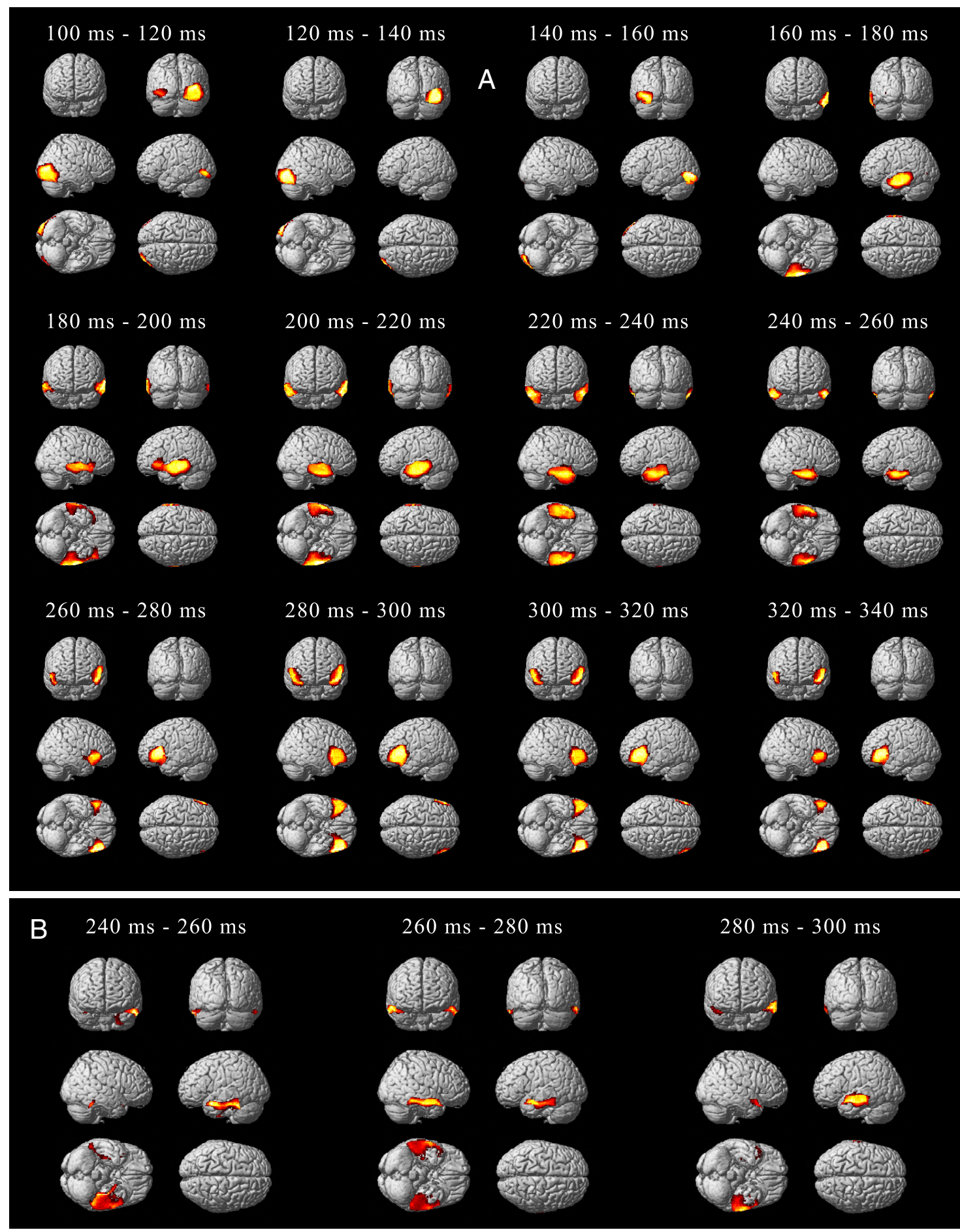

Figure 3. Source reconstruction averaged over $20 \mathrm{~ms}$ time windows from 100 to $340 \mathrm{~ms}$. $A$, Paired $t$ test of cortical source energy of the common pathway for the phonological and semantic network ( $p<0.05$, FWE small volume correction). B, Paired $t$ test between semantic and phonological condition between 240 and 300 ms ( $p<0.05$, FWE small volume correction).

anterior and superior temporal regions in the semantic task compared with the phonological task.

\section{Spatiotemporal integration of phonological and} semantic processes

Group source reconstruction showed activation of a predominant left cerebral network classically involved in language processing and including left OT, left posterior IT, left posterior STS, bilateral AT, and bilateral IFG.
Early activation of OT suggests sublexical orthographic processing in that region (Maurer et al., 2005; Dien, 2009). OT has been reported to be sensitive to letter string analysis (Cohen et al., 2000; Tarkiainen et al., 2002) and could be involved in the segmentation of word and pseudo-word into bigram and trigram entities (graphemes) (Dehaene et al., 2002; Jobard et al., 2003).

Classically, increased complexity of stimulus processing is associated with posterior-to-anterior brain gradient accord- 


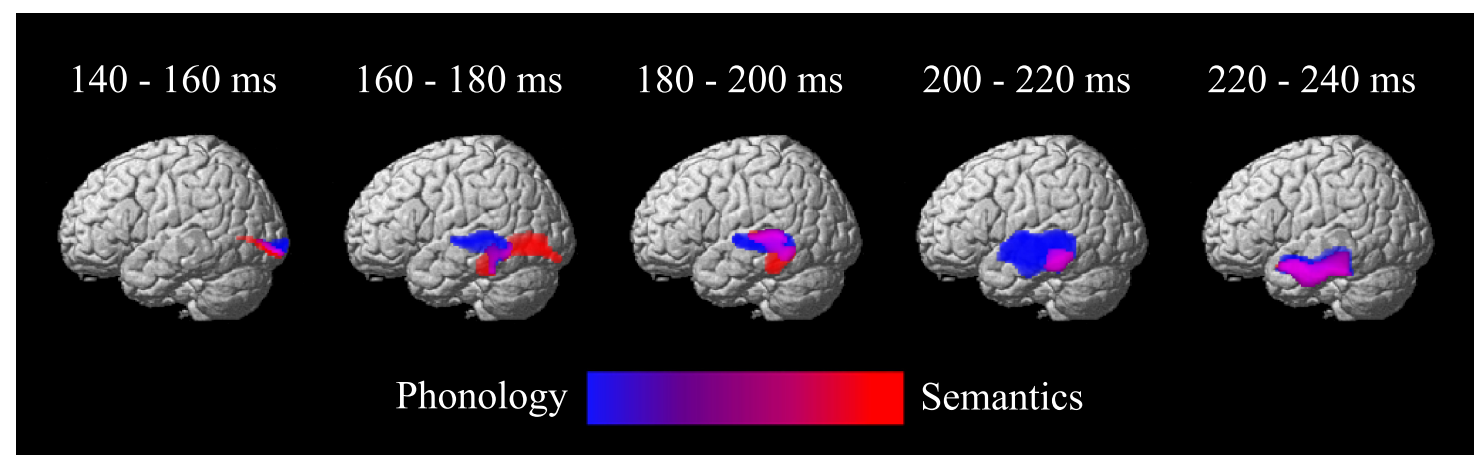

Figure 4. Source reconstruction averaged over $20 \mathrm{~ms}$ time windows of the phonological (blue) and semantic (red) networks from 140 to $240 \mathrm{~ms}$ ( $p<0.05$, FWE small volume correction).

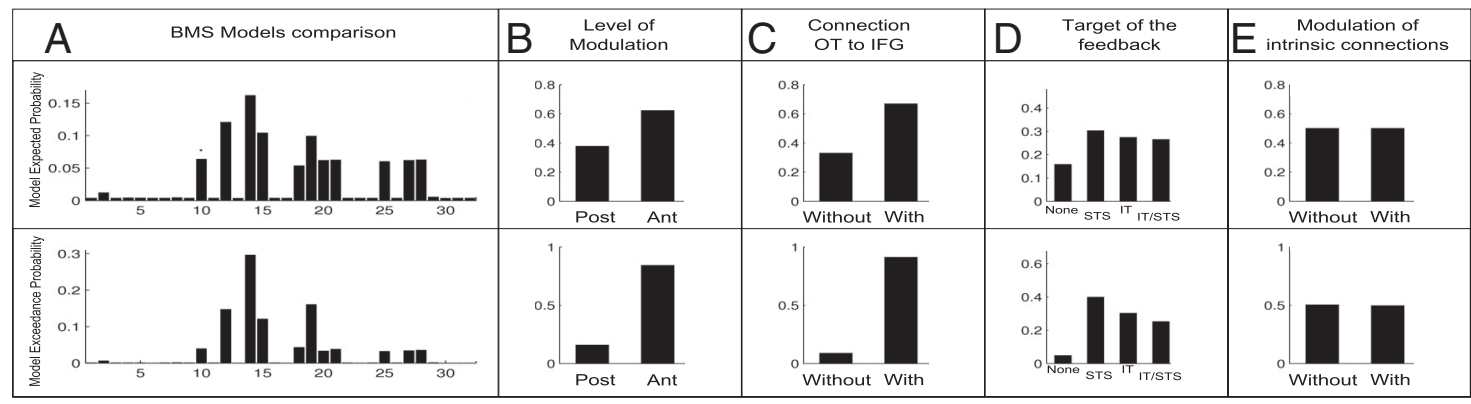

Figure 5. $\quad \boldsymbol{A}-\boldsymbol{E}$, Bayesian model selection between the 32 models $(\boldsymbol{A})$ and between families of models: with early (post) or late (ant) level of modulation (B); with or without a direct connection from OT to IFG (C); without feedback from IFG, with a feedback on STS and with a feedback on IT or both (D); and with or without intrinsic modulation on all sources (E). Models and families were compared with a random-effect analysis.

ing to the change in stimulus representation, from unimodal to multimodal and amodal (Nobre et al., 1994; Büchel et al., 1998; Binder et al., 2009; Dien, 2009). In this framework, during phonological task, rapid activation (160-200 ms) of the posterior STS involved in multimodal representation (Beauchamp et al., 2004; Reale et al., 2007) may account for direct grapheme-to-phoneme conversion (Simos et al., 2000). During semantic task, rapid activation ( $160-220 \mathrm{~ms})$ of the posterior part of inferior temporal gyrus, also involved in multimodal representation (Price and Devlin, 2003; Dien, 2009; Kherif et al., 2011), may be related to graphemic to lexical matching within mental lexicon (Martin, 2007; Lau et al., 2008). The rapid segregation of phonological and lexical pathways is in line with results reported in Richardson et al. (2011). From 180 to $220 \mathrm{~ms}$, coactivation of posteroinferior and superior temporal regions would be related to lexicophonological representations of words (Wise et al., 2001; Hickok and Poeppel, 2007; Gagnepain et al., 2008).

In the present study, the anterior part of the inferior temporal lobe was subsequently activated for both tasks, from 240 to $280 \mathrm{~ms}$, in agreement with similar results provided by an MEG study (Fujimaki et al., 2009). However, our results revealed longer involvement of the activation of the anterior part of inferior temporal lobe for semantic compared with phonological task. This result confirms the crucial role of this region for the semantic access (Mummery et al., 2000; Marinkovic et al., 2003; Bright et al., 2004; Gorno-Tempini et al., 2004; Noppeney et al., 2007; Fujimaki et al., 2009; Lambon Ralph et al., 2009; Binney et al., 2010; Visser et al., 2010). This region could serve as a hub within the widespread semantic system. Its role would be to convert lexical into amodal representations (Marinkovic et al., 2003; Patterson et al., 2007; Lau et al., 2008; Pulvermüller et al., 2010).
Finally, the left IFG was robustly and equally activated for both tasks from 280 to $340 \mathrm{~ms}$. The activity in this region may suggest top-down control of semantic memory to guide retrieval and selection of conceptual information stored within posterior temporal cortex (Thompson-Schill et al., 1998; Badre et al., 2005).

Dynamic causal modeling of the written language network DCM was used here to further address effective connectivity underlying the observed sequence of activation. In particular, we concentrated on the multiple routes model (Jobard et al., 2003; Richardson et al., 2011) using the ROIs discussed above. A ventral pathway (OT/IT/AT) and a dorsal pathway (OT/STS/AT) were considered, hypothesized to segregate semantic and phonological processing, respectively. Those regions also embedded an intermediate lexicophonologic pathway (OT/IT/STS/AT). Specifically, 32 DCM models were tested to address three specific hypotheses through Bayesian model selection: (1) the level in the cortical hierarchy of connectivity modulation within the dorsal and ventral routes, (2) the presence of a fast pathway toward IFG that could facilitate the top-down influence of IFG on lower regions, and (3) the feedback pathway of IFG on STS or IT or both. These models recapitulate to some extent the pathways from basic visual to higher-order temporal language areas proposed in Richardson et al. (2011): OT/IT/AT, OT/STS/AT, and OT/IT/STS/AT.

We detected significant modulation of effective connectivity on the forward connection between IT and AT, which was increased during the semantic condition. These regions are connected anatomically via the longitudinal fasciculus (Crosby, 1963; Catani et al., 2003) and are functionally included in the pathway OT/IT/AT proposed by Richardson et al. (2011). This result is in agreement with models suggesting that written 
A

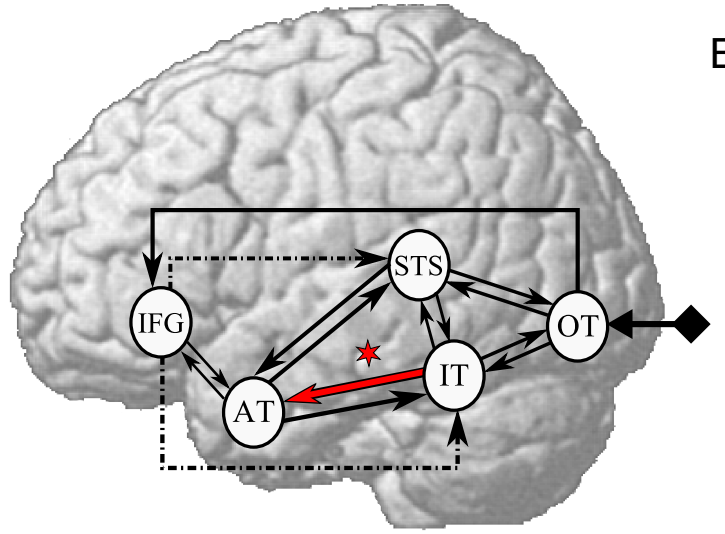

B

Average connectivity parameter from IT to AT (log value)

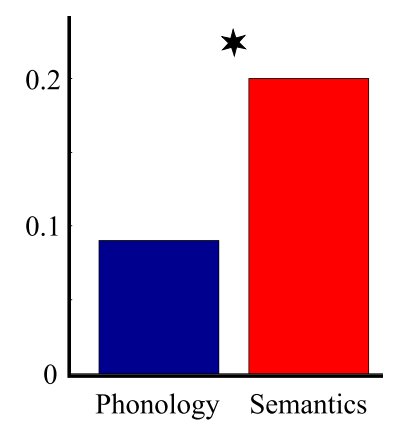

C
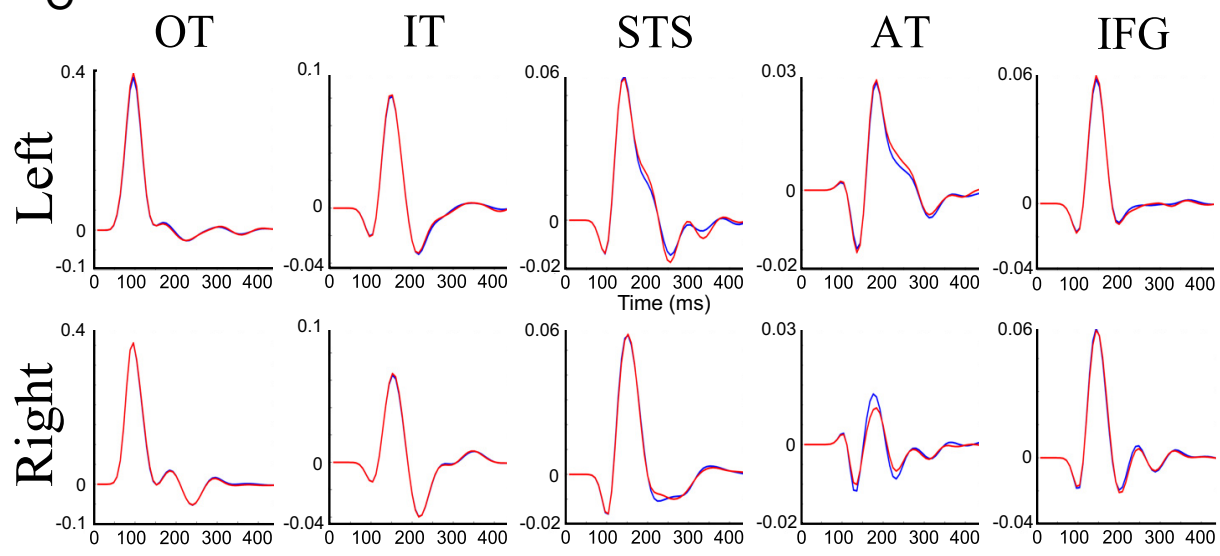

Figure 6. Winning model family composed of a direct connection from OT to IFG, a late level of modulation and a feedback from IFG either to STS or IT or both. A, The red arrow indicates higher connectivity for semantics than for phonology $\left({ }^{*} p<0.05\right.$, Bonferroni corrected). $\boldsymbol{B}$, Corresponding connectivity parameters obtained after BMA and averaged over subjects; they were significantly different between conditions. C, Group cortical time series of the same model family (blue, phonology; red, semantics).

words can access semantics independently of phonology (Seidenberg and McClelland, 1989; Harm and Seidenberg, 2004) by direct graphemic-lexical matching within IT (Lau et al., 2008) and amodal representation within AT (Marinkovic et al., 2003; Patterson et al., 2007). Furthermore, increased connectivity between IT and STS during semantic condition may account for the proposed pathway OT/IT/STS/AT of Richardson et al. (2011), which possibly reflects the integration between lexical and phonological representations of the word (Wise et al., 2001; Hickok and Poeppel, 2007; Gagnepain et al., 2008). The increase of connectivity between IT and STS was, however, marginal, thus reflecting a certain degree of intersubject variability of word processing within the temporal lobe. The pathway OT/STS/AT proposed by Richardson et al. (2011), which may be purely phonological, was not revealed by our analysis. This discrepancy could be due to the fact that our tasks could have equally activated this pathway, particularly the connection between STS and AT.

The comparison between models revealed robust and direct connection from OT to IFG. It allows early activation of frontal cortex during visual language (Cornelissen et al., 2009) and object recognition (Bar, 2003; Bar et al., 2006) tasks, possibly by the means of direct anatomical connections between early visual regions and frontal cortex (Barbas, 2000; Kringelbach and Rolls, 2004; Wakana et al., 2004; Makris et al., 2005; Bürgel et al., 2006). Functionally, visual stimuli may activate very early IFG to prime the language network for the upcoming cross-modal interaction between visual and language systems for word recognition (Cornelissen et al., 2009). Additionally, IFG may exert feedback control on regions involved in lower level analysis of the written words (Gold et al., 2006; Kherif et al., 2011). However, the precise role and the target region of this feedback remain unclear. The feedback may also reflect attentional processes to control integration of bottom-up processes by lower-level analysis regions depending on the task demand (Thompson-Schill et al., 2005; Gold et al., 2006; Twomey et al., 2011). The target of the feedback could also depend on the strategy adopted by the subject. Indeed, particularly in the phonological task, subjects could have adopted a phonological strategy, which would be implemented with a feedback on STS, but they could also have used a more orthographic strategy by detecting the target at the grapheme level with a feedback on IT. Further investigations are needed to disentangle this issue. Another limitation of this study regarding IFG is that we were unable to reproduce the late activation of IFG with the tested DCMs. Because we also identified that right parietal activity was also poorly fitted at the scalp level, we can hypothesize that, although tested DCMs were well suited to model fast activation of temporal regions (scope of this study), an additional dorsal pathway could have been required to facilitate the fit of late $(>300 \mathrm{~ms})$ frontal activity, e.g., by the means of reciprocal parietal connections with posterior temporal regions and IFG. It would be interesting to clarify this issue in future studies. 


\section{References}

Alario FX, Schiller NO, Domoto-Reilly K, Caramazza A (2003) The role of phonological and orthographic information in lexical selection. Brain Lang 84:372-398.

Badre D, Poldrack RA, Paré-Blagoev EJ, Insler RZ, Wagner AD (2005) Dissociable controlled retrieval and generalized selection mechanisms in ventrolateral prefrontal cortex. Neuron 47:907-918.

Bar M (2003) A cortical mechanism for triggering top-down facilitation in visual object recognition. J Cogn Neurosci 15:600-609.

Bar M, Kassam KS, Ghuman AS, Boshyan J, Schmidt AM, Dale AM, Hämäläinen MS, Marinkovic K, Schacter DL, Rosen BR, Halgren E (2006) Topdown facilitation of visual recognition. Proc Natl Acad Sci U S A 103:449-454.

Barbas H (2000) Connections underlying the synthesis of cognition, memory, and emotion in primate prefrontal cortices. Brain Res Bull 52:319-330.

Beauchamp MS, Lee KE, Argall BD, Martin A (2004) Integration of auditory and visual information about objects in superior temporal sulcus. Neuron 41:809-823.

Berndt RS, D’Autrechy CL, Reggia JA (1994) Functional pronunciation units in English words. J Exp Psychol Learn Mem Cogn 20:977-991.

Billingsley RL, McAndrews MP, Crawley AP, Mikulis DJ (2001) Functional MRI of phonological and semantic processing in temporal lobe epilepsy. Brain 124:1218-1227.

Binder JR, Desai RH, Graves WW, Conant LL (2009) Where is the semantic system? A critical review and meta-analysis of 120 functional neuroimaging studies. Cereb Cortex 19:2767-2796.

Binney RJ, Embleton KV, Jefferies E, Parker GJ, Lambon Ralph MA (2010) The ventral and inferolateral aspects of the anterior temporal lobe are crucial in semantic memory: evidence from a novel direct comparison of distortion-corrected fMRI, rTMS, and semantic dementia. Cereb Cortex 20:2728-2738.

Brem S, Lang-Dullenkopf A, Maurer U, Halder P, Bucher K, Brandeis D (2005) Neurophysiological signs of rapidly emerging visual expertise for symbol strings. Neuroreport 16:45-48.

Bright P, Moss H, Tyler LK (2004) Unitary vs multiple semantics: PET studies of word and picture processing. Brain Lang 89:417-432.

Büchel C, Price C, Friston K (1998) A multimodal language region in the ventral visual pathway. Nature 394:274-277.

Bürgel U, Amunts K, Hoemke L, Mohlberg H, Gilsbach JM, Zilles K (2006) White matter fiber tracts of the human brain: three-dimensional mapping at microscopic resolution, topography and intersubject variability. Neuroimage 29:1092-1105.

Catani M, Jones DK, Donato R, Ffytche DH (2003) Occipito-temporal connections in the human brain. Brain 126:2093-2107.

Cohen L, Dehaene S (2004) Specialization within the ventral stream: the case for the visual word form area. Neuroimage 22:466-476.

Cohen L, Dehaene S, Naccache L, Lehéricy S, Dehaene-Lambertz G, Hénaff MA, Michel F (2000) The visual word form area: spatial and temporal characterization of an initial stage of reading in normal subjects and posterior split-brain patients. Brain 123:291-307.

Cornelissen PL, Kringelbach ML, Ellis AW, Whitney C, Holliday IE, Hansen PC (2009) Activation of the left inferior frontal gyrus in the first $200 \mathrm{~ms}$ of reading: evidence from magnetoencephalography (MEG). PLoS ONE 4:e5359.

Cousin E, Peyrin C, Pichat C, Lamalle L, Le Bas JF, Baciu M (2007) Functional MRI approach for assessing hemispheric predominance of regions activated by a phonological and a semantic task. Eur J Radiol 63:274-285.

Crosby EC (1963) Correlative anatomy of the nervous system. Acad Med 38:526.

Damasio AR, Damasio H (1983) The anatomic basis of pure alexia. Neurology 33:1573-1583.

Dapretto M, Bookheimer SY (1999) Form and content: dissociating syntax and semantics in sentence comprehension. Neuron 24:427-432.

David O, Kiebel SJ, Harrison LM, Mattout J, Kilner JM, Friston KJ (2006) Dynamic causal modeling of evoked responses in EEG and MEG. Neuroimage 30:1255-1272.

Dehaene S, Le Clec'H G, Poline JB, Le Bihan D, Cohen L (2002) The visual word form area: a prelexical representation of visual words in the fusiform gyrus. Neuroreport 13:321-325.

Dien J (2009) The neurocognitive basis of reading single words as seen through early latency ERPs: a model of converging pathways. Biol Psychol 80:10-22.
Felleman DJ, Van Essen DC (1991) Distributed hierarchical processing in the primate cerebral cortex. Cereb Cortex 1:1-47.

Fiez JA, Balota DA, Raichle ME, Petersen SE (1999) Effects of lexicality, frequency, and spelling-to-sound consistency on the functional anatomy of reading. Neuron 24:205-218.

Friston K, Harrison L, Daunizeau J, Kiebel S, Phillips C, Trujillo-Barreto N, Henson R, Flandin G, Mattout J (2008) Multiple sparse priors for the M/EEG inverse problem. Neuroimage 39:1104-1120.

Fujimaki N, Hayakawa T, Ihara A, Wei Q, Munetsuna S, Terazono Y, Matani A, Murata T (2009) Early neural activation for lexico-semantic access in the left anterior temporal area analyzed by an fMRI-assisted MEG multidipole method. Neuroimage 44:1093-1102.

Gagnepain P, Chételat G, Landeau B, Dayan J, Eustache F, Lebreton K (2008) Spoken word memory traces within the human auditory cortex revealed by repetition priming and functional magnetic resonance imaging. J Neurosci 28:5281-5289.

Gaillard R, Naccache L, Pinel P, Clémenceau S, Volle E, Hasboun D, Dupont S, Baulac M, Dehaene S, Adam C, Cohen L (2006) Direct intracranial, FMRI, and lesion evidence for the causal role of left inferotemporal cortex in reading. Neuron 50:191-204.

Gitelman DR, Nobre AC, Sonty S, Parrish TB, Mesulam MM (2005) Language network specializations: an analysis with parallel task designs and functional magnetic resonance imaging. Neuroimage 26:975-985.

Gold BT, Balota DA, Jones SJ, Powell DK, Smith CD, Andersen AH (2006) Dissociation of automatic and strategic lexical-semantics: functional magnetic resonance imaging evidence for differing roles of multiple frontotemporal regions. J Neurosci 26:6523-6532.

Gorno-Tempini ML, Dronkers NF, Rankin KP, Ogar JM, Phengrasamy L, Rosen HJ, Johnson JK, Weiner MW, Miller BL (2004) Cognition and anatomy in three variants of primary progressive aphasia. Ann Neurol 55:335-346.

Greenblatt SH (1976) Subangular alexia without agraphia or hemianopsia. Brain Lang 3:229-245.

Gros H, Doyon B, Rioual K, Celsis P (2002) Automatic grapheme processing in the left occipitotemporal cortex. Neuroreport 13:1021-1024.

Harm MW, Seidenberg MS (2004) Computing the meanings of words in reading: cooperative division of labor between visual and phonological processes. Psychol Rev 111:662-720.

Henderson VW (1986) Anatomy of posterior pathways in reading: a reassessment. Brain Lang 29:119-133.

Herbster AN, Mintun MA, Nebes RD, Becker JT (1997) Regional cerebral blood flow during word and nonword reading. Hum Brain Mapp 5:84-92.

Hickok G, Poeppel D (2007) The cortical organization of speech processing. Nat Rev Neurosci 8:393-402.

Jobard G, Crivello F, Tzourio-Mazoyer N (2003) Evaluation of the dual route theory of reading: a metanalysis of 35 neuroimaging studies. Neuroimage 20:693-712.

Kherif F, Josse G, Price CJ (2011) Automatic top-down processing explains common left occipito-temporal responses to visual words and objects. Cereb Cortex 21:103-114.

Kiebel SJ, David O, Friston KJ (2006) Dynamic causal modelling of evoked responses in EEG/MEG with lead field parameterization. Neuroimage 30:1273-1284.

Kilner JM, Friston KJ (2010) Topological inference for EEG and MEG. Ann Appl Statist 4:1272-1290.

Koessler L, Maillard L, Benhadid A, Vignal J, Braun M, Vespignani H (2007) Spatial localization of EEG electrodes. Neurophysiologie Clinique/Clin Neurophysiol 37:97-102.

Kringelbach ML, Rolls ET (2004) The functional neuroanatomy of the human orbitofrontal cortex: evidence from neuroimaging and neuropsychology. Prog Neurobiol 72:341-372.

Lambon Ralph MA, Pobric G, Jefferies E (2009) Conceptual knowledge is underpinned by the temporal pole bilaterally: convergent evidence from rTMS. Cereb Cortex 19:832-838.

Lau EF, Phillips C, Poeppel D (2008) A cortical network for semantics: (de) constructing the N400. Nat Rev Neurosci 9:920-933.

Leff AP, Crewes H, Plant GT, Scott SK, Kennard C, Wise RJ (2001) The functional anatomy of single-word reading in patients with hemianopic and pure alexia. Brain 124:510-521.

Litvak V, Friston K (2008) Electromagnetic source reconstruction for group studies. Neuroimage 42:1490-1498.

Lurito JT, Kareken DA, Lowe MJ, Chen SH, Mathews VP (2000) Compari- 
son of rhyming and word generation with FMRI. Hum Brain Mapp 10:99-106.

Makris N, Kennedy DN, McInerney S, Sorensen AG, Wang R, Caviness VS Jr, Pandya DN (2005) Segmentation of subcomponents within the superior longitudinal fascicle in humans: a quantitative, in vivo, DT-MRI study. Cereb Cortex 15:854-869.

Marinkovic K, Dhond RP, Dale AM, Glessner M, Carr V, Halgren E (2003) Spatiotemporal dynamics of modality-specific and supramodal word processing. Neuron 38:487-497.

Martin A (2007) The representation of object concepts in the brain. Annu Rev Psychol 58:25-45.

Mattout J, Henson RN, Friston KJ (2007) Canonical source reconstruction for MEG. Comput Intell Neurosci 2007:67613.

Maurer U, Brandeis D, McCandliss BD (2005) Fast, visual specialization for reading in English revealed by the topography of the N170 ERP response. Behav Brain Funct 1:13.

McDermott KB, Petersen SE, Watson JM, Ojemann JG (2003) A procedure for identifying regions preferentially activated by attention to semantic and phonological relations using functional magnetic resonance imaging. Neuropsychologia 41:293-303.

Mummery CJ, Patterson K, Price CJ, Ashburner J, Frackowiak RS, Hodges JR (2000) A voxel-based morphometry study of semantic dementia: relationship between temporal lobe atrophy and semantic memory. Ann Neurol 47:36-45.

New B, Pallier C, Brysbaert M, Ferrand L (2004) Lexique 2: a new French lexical database. Behav Res Methods Instrum Comput 36:516-524.

Nobre AC, Allison T, McCarthy G (1994) Word recognition in the human inferior temporal lobe. Nature 372:260-263.

Noppeney U, Patterson K, Tyler LK, Moss H, Stamatakis EA, Bright P, Mummery C, Price CJ (2007) Temporal lobe lesions and semantic impairment: a comparison of herpes simplex virus encephalitis and semantic dementia. Brain 130:1138-1147.

Oldfield RC (1971) The assessment and analysis of handedness: the Edinburgh inventory. Neuropsychologia 9:97-113.

Patterson K, Nestor PJ, Rogers TT (2007) Where do you know what you know? The representation of semantic knowledge in the human brain. Nat Rev Neurosci 8:976-987.

Penny WD, Stephan KE, Mechelli A, Friston KJ (2004) Comparing dynamic causal models. Neuroimage 22:1157-1172.

Penny WD, Stephan KE, Daunizeau J, Rosa MJ, Friston KJ, Schofield TM, Leff AP (2010) Comparing families of dynamic causal models. PLoS Comput Biol 6:e1000709.

Perrone-Bertolotti M, Pichat C, Le Bas JF, Baciu A, Baciu M (2011) Functional MRI evidence for modulation of cerebral activity by grapheme-to-phoneme conversion in French, and by the variable of gender. J Neurolinguist 24:507-520.

Phillips C, Mattout J, Friston KJ (2007) Forwards models for EEG. In: Statistical parametric mapping: the analysis of functional brain images (Penny WD, Friston KJ, Ashburner JT, Kiebel SJ, Nichols TE, eds), pp 352-366. London: Elsevier.

Price CJ, Devlin JT (2003) The myth of the visual word form area. Neuroimage 19:473-481.

Pugh KR, Shaywitz BA, Shaywitz SE, Constable RT, Skudlarski P, Fulbright RK, Bronen RA, Shankweiler DP, Katz L, Fletcher JM, Gore JC (1996) Cerebral organization of component processes in reading. Brain 119:1221-1238.

Pulvermüller F, Cooper-Pye E, Dine C, Hauk O, Nestor PJ, Patterson K (2010) The word processing deficit in semantic dementia: all categories are equal, but some categories are more equal than others. J Cogn Neurosci 22:2027-2041.

Reale RA, Calvert GA, Thesen T, Jenison RL, Kawasaki H, Oya H, Howard MA, Brugge JF (2007) Auditory-visual processing represented in the human superior temporal gyrus. Neuroscience 145:162-184.

Richardson FM, Seghier ML, Leff AP, Thomas MS, Price CJ (2011) Multiple routes from occipital to temporal cortices during reading. J Neurosci 31:8239-8247.

Seghier ML, Lazeyras F, Pegna AJ, Annoni JM, Zimine I, Mayer E, Michel CM, Khateb A (2004) Variability of fMRI activation during a phonological and semantic language task in healthy subjects. Hum Brain Mapp 23:140-155.

Seidenberg MS, McClelland JL (1989) A distributed, developmental model of word recognition and naming. Psychol Rev 96:523-568.

Simon G, Bernard C, Lalonde R, Rebaï M (2006) Orthographic transparency and grapheme-phoneme conversion: an ERP study in Arabic and French readers. Brain Res 1104:141-152.

Simos PG, Breier JI, Wheless JW, Maggio WW, Fletcher JM, Castillo EM, Papanicolaou AC (2000) Brain mechanisms for reading: the role of the superior temporal gyrus in word and pseudoword naming. Neuroreport 11:2443-2447.

Stephan KE, Penny WD, Daunizeau J, Moran RJ, Friston KJ (2009) Bayesian model selection for group studies. Neuroimage 46:1004-1017.

Tarkiainen A, Cornelissen PL, Salmelin R (2002) Dynamics of visual feature analysis and object-level processing in face versus letter-string perception. Brain 125:1125-1136.

Thompson-Schill SL, Swick D, Farah MJ, D’Esposito M, Kan IP, Knight RT (1998) Verb generation in patients with focal frontal lesions: a neuropsychological test of neuroimaging findings. Proc Natl Acad Sci U S A 95:15855-15860.

Thompson-Schill SL, Bedny M, Goldberg RF (2005) The frontal lobes and the regulation of mental activity. Curr Opin Neurobiol 15:219-224.

Trujillo-Barreto NJ, Aubert-Vázquez E, Valdés-Sosa PA (2004) Bayesian model averaging in EEG/MEG imaging. Neuroimage 21:1300-1319.

Twomey T, Kawabata Duncan KJ, Price CJ, Devlin JT (2011) Top-down modulation of ventral occipito-temporal responses during visual word recognition. Neuroimage 55:1242-1251.

Vandenberghe R, Price C, Wise R, Josephs O, Frackowiak RS (1996) Functional anatomy of a common semantic system for words and pictures. Nature 383:254-256.

Vigneau M, Beaucousin V, Hervé PY, Duffau H, Crivello F, Houdé O, Mazoyer B, Tzourio-Mazoyer N (2006) Meta-analyzing left hemisphere language areas: phonology, semantics, and sentence processing. Neuroimage 30:1414-1432.

Visser M, Jefferies E, Lambon Ralph MA (2010) Semantic processing in the anterior temporal lobes: a meta-analysis of the functional neuroimaging literature. J Cogn Neurosci 22:1083-1094.

Wakana S, Jiang H, Nagae-Poetscher LM, van Zijl PC, Mori S (2004) Fiber tract-based atlas of human white matter anatomy. Radiology 230:77-87.

Walter N, Cliche S, Joubert S, Beauregard M, Joanette Y (2001) Graphemephoneme processing of single words. Brain Cogn 46:295-299.

Warrington EK, Shallice T (1980) Word-form dyslexia. Brain 103:99-112.

Wise RJ, Scott SK, Blank SC, Mummery CJ, Murphy K, Warburton EA (2001) Separate neural subsystems within 'Wernicke's area'. Brain 124:83-95.

Zatorre RJ, Evans AC, Meyer E, Gjedde A (1992) Lateralization of phonetic and pitch discrimination in speech processing. Science 256:846-849. 